\title{
The response of the apparent receptive speech disorder of Parkinson's disease to speech therapy
}

\author{
SHEILA SCOTT, FI CAIRD \\ From the University Department of Geriatric Medicine, Southern General Hospital, Glasgow, UK
}

SUMMARY Eleven patients with Parkinson's disease were tested for prosodic abnormality, on three tests of speech production (of angry, questioning, and neutral statement forms), and four tests of appreciation of the prosodic features of speech and facial expression. The tests were repeated after a control period of two weeks without speech therapy and were not substantially different. After two weeks of intensive domiciliary prosodic therapy, the prosodic abnormality score was improved, as were three of the four tests of recognition of the prosodic features of speech and facial expression, and two of the three tests of production (of angry and questioning forms). The apparent receptive disorder of speech in Parkinson's disease can thus respond to therapy. Possible mechanisms of improvement are briefly discussed.

Prosody (that is, variation of intonation, pitch, volume, rate, and rhythm) has an important semantic and emotional role in communication. ${ }^{1}$ Disordered prosody underlies the speech disorder in Parkinson's disease and has important consequences. ${ }^{2}$ Evidence for an apparent receptive element in this dysprosody has been presented. ${ }^{3}$ Patients with Parkinson's disease were found to be unable to appreciate the prosodic aspects of their own and others' speech and facial expression. They could produce statements in a neutral form normally, but not in angry or questioning forms. This abnormality seemed to be an early feature of the disease. Specific types of speech therapy have been shown to be effective in Parkinson's disease, in improving prosody and with it functional communication. ${ }^{24}$ The present study was intended to investigate the possibility that therapy might also benefit the apparent receptive disorder.

\section{Patients and methods}

Eleven patients with Parkinson's disease were studied, six men and five women (age 49-83 years, average 65; average duration of disease 7 years). All were taking a variety

Address for reprint requests: Professor FI Caird, University Department of Geriatric Medicine, Southern General Hospital, Glasgow G51 4TF, UK.

Received 5 August 1983

Accepted 14 September 1983 of drugs: nine levodopa in combination form, three bromocriptine, three amantadine, seven anticholinergic drugs, and seven benzodiazepines. The criteria for selection and exclusion were as before. ${ }^{3}$ All patients performed normally on an auditory discrimination test and were without significant hearing impairment. All also performed normally on the Shortened Schuell Test, ${ }^{5}$ and had no demonstrable abnormality of language. All scored 25 points or more on a 33-point memory and information test (see ref. 6). All but one patient were able to perform the Colour/Form Sorting Test. ${ }^{7}$ The patients were tested for a prosodic abnormality score, ${ }^{2}$ and, as previously described, ${ }^{3}$ with seven tests of appreciation of prosodic contrasts and of facial expression, and production of the prosodic features of speech.

The patients were assessed and treated at home, always at the same time of day. Three assessments were made: (1) before, (2) after two weeks without treatment and, (3) after ten hourly sessions of intensive domiciliary prosodic therapy. When the results of the first and second assessments differed, they were averaged for purposes of comparison with the results in the third.

\section{Results}

The table shows the results of the prosodic abnormality score and the tests of appreciation and production of prosodic contrasts. There was no difference between the first and second assessments, before and after the control period without treatment, except in test 6 , but the prosodic abnormality 
Table Mean scores $( \pm S D)$ in three assessments

\begin{tabular}{|c|c|c|c|c|c|}
\hline Test & $\begin{array}{l}\text { Maximum } \\
\text { score }\end{array}$ & $\begin{array}{l}\text { Assessments } \\
1\end{array}$ & 2 & 3 & $\begin{array}{l}p \text { for significance of } \\
\text { difference between assessments } \\
2 \& 3 \text { (paired } t \text { test) }\end{array}$ \\
\hline Prosodic Abnormality & 7 & \multirow{2}{*}{$\begin{array}{c}4.64 \\
( \pm 1.29) \\
6.91 \\
( \pm 1.76)\end{array}$} & \multirow{2}{*}{$\begin{array}{c}4.45 \\
( \pm 1.29) \\
6.91 \\
( \pm 1 \cdot 81)\end{array}$} & \multirow{2}{*}{$\begin{array}{c}2.36 \\
( \pm 1 \cdot 12) \\
7.82 \\
( \pm 0.40)\end{array}$} & \\
\hline $\begin{array}{l}\text { 1. Discrimination of Prosodic } \\
\text { Contrasts }\end{array}$ & 8 & & & & $<0.05$ \\
\hline $\begin{array}{l}\text { 2. Matching Speech and Facial } \\
\text { Expression }\end{array}$ & 1 & $\begin{array}{c}0.55 \\
( \pm 0.52)\end{array}$ & $\begin{array}{c}0.55 \\
( \pm 0.52)\end{array}$ & $\begin{array}{c}1.00 \\
( \pm 0 \cdot 00)\end{array}$ & $<0.001$ \\
\hline $\begin{array}{l}\text { 3. Discrimination of Affective } \\
\text { and Grammatical Functions of } \\
\text { Prosody }\end{array}$ & 8 & $\begin{array}{c}5 \cdot 09 \\
( \pm 1 \cdot 38)\end{array}$ & $\begin{array}{c}5 \cdot 18 \\
( \pm 1 \cdot 47)\end{array}$ & $\begin{array}{c}7 \cdot 27 \\
( \pm 1 \cdot 27)\end{array}$ & $<0.05$ \\
\hline $\begin{array}{l}\text { 4. Discrimination of Semantic } \\
\text { Functions of Prosody }\end{array}$ & 4 & $\begin{array}{c}1.82 \\
( \pm 0.98)\end{array}$ & $\begin{array}{c}1.82 \\
( \pm 0 \cdot 87)\end{array}$ & $\begin{array}{c}3.36 \\
( \pm 0.81)\end{array}$ & $<0.05$ \\
\hline $\begin{array}{l}\text { 5. Production of Angry Speech } \\
\text { Tone }\end{array}$ & 3 & $\begin{array}{c}0.91 \\
( \pm 1.04)\end{array}$ & $\begin{array}{c}0.73 \\
( \pm 0.79)\end{array}$ & $\begin{array}{c}2.55 \\
( \pm 0.52)\end{array}$ & $<0.025$ \\
\hline $\begin{array}{l}\text { 6. Production of Questioning } \\
\text { Speech Tone }\end{array}$ & 3 & $\begin{array}{c}0.27 \\
( \pm 0 \cdot 47)\end{array}$ & $\begin{array}{c}0.64 \\
( \pm 0.81)^{*}\end{array}$ & $\begin{array}{c}2.09 \\
( \pm 1 \cdot 04)\end{array}$ & $<0.01$ \\
\hline $\begin{array}{l}\text { 7. Production of Neutral } \\
\text { Statement }\end{array}$ & 3 & $\begin{array}{r}3 \cdot 00 \\
( \pm 0 \cdot 0)\end{array}$ & $\begin{array}{r}3 \cdot 00 \\
( \pm 0 \cdot 0)\end{array}$ & $\begin{array}{r}3.00 \\
( \pm 0 \cdot 0)\end{array}$ & NS \\
\hline
\end{tabular}

*Significance of difference between tests $1 \& 2$ p $<0.001$

score and tests 1-6 inclusive all showed significant improvement between the second and third assessments, that is, after 2 weeks' therapy. In particular test 2 (matching speech and facial expression) returned to normal in all the five cases in which it had been abnormal. Test 7 (production of a neutral statement) was normal in all cases on all occasions.

\section{Discussion}

The apparent receptive component in the Parkinsonian speech disorder is unexplained. ${ }^{3}$ It may underlie much of the dysprosody, because patients are unable to monitor this aspect of their own and others' speech and facial expression. This has a considerable impact on speech, and important adverse psychological and social consequences for many patients with Parkinson's disease and their relatives. ${ }^{12}$ The present study shows that the abnormality is stable, in the sense that the results of tests for it do not undergo substantial or significant change over a two-week period without treatment. The abnormality is still present despite presumably optimal drug treatment, and is therefore not totally reversed by drug therapy. The results of the present study show clearly that it can and does improve with speech therapy over a short period of time. Abnormality of prosody also improves, and with it intelligibility of speech and social communication. ${ }^{2}$ This last probably depends as much upon others' attitudes to the abnormality, and their perception of the patient as apathetic, demented, or cold and unfeeling, ${ }^{1}$ as on the patient's own view of himself and his difficulty.

It may be asked how an apparent receptive disorder can improve, and it can only be answered that it does so. There are, however, interesting and suggestive parallels in the field of speech. Receptive dysphasia due to stroke improves with time and speech therapy ${ }^{8}$ and the speech of deaf children does so, in part at least, with prosodic therapy. ${ }^{9}$ In both these situations an undoubted receptive disorder of speech improves, probably because attention is directed to it by therapy which aims at facilitating the use of visual, auditory and tactile feedback mechanisms, and so at enabling the patient to monitor his own speech, particularly in its important prosodic aspects. This results in both cases in better intelligibility of speech. Changes of a similar nature may be taking place during the treatment of the Parkinsonian speech disorder, and result in its improvement.

We thank the Trustees of the David Cargill Fund for their financial support, and the members of the Edinburgh Branch of the Parkinson's Disease Society and patients for their participation. We are also grateful to Dr MKC MacMahon for his guidance during the study, and to Mr D Sutton and the staff of the Regional Physics Department (Glasgow and West of Scotland) for their advice and assistance throughout the study. 


\section{References}

${ }^{1}$ Monrad Krohn GH. The third element of speech: prosody in the neuropsychiatric clinic. J Ment Sci 1957;103:326-31.

${ }^{2}$ Scott S, Caird FI. Speech therapy in Parkinson's disease. J Neurol Neurosurg Psychiatry 1983;46:140-8.

${ }^{3}$ Scott S, Caird FI, Williams BO. Evidence for apparent sensory speech disorder in Parkinson's disease. $J$ Neurol Neurosurg Psychiatry, (in press), 1984.

${ }^{4}$ Scott S, Caird FI. Speech therapy for patients with Parkinson's disease. $\mathrm{Br}$ Med J 1981;283:1088.

5 Powell G, Bailey S, Clark L. A very shortened version of the Minnesota aphasia test. Br J Soc Clin Psychol 1980;19:189-94.
- Caird FI, Kennedy RD, Williams BO. Practical Rehabilitation of the Elderly. London: Pitman 1983, 120-2.

${ }^{7}$ Goldstein K. Language and Language Disturbances. New York: Grune and Stratton 1948, 111.

${ }^{8}$ Taylor Sarno M. The status of research in recovery from aphasia. In: Lebrun Y, Hoops $\mathbf{R}$ eds Recovery in Aphasics. Neurolinguistics 4. Amsterdam: Swets and Zeitlinger B.V. 1976, 13-22.

${ }^{9}$ Stark R. Speech of the Hearing Impaired Child. In: Hearing and Hearing Impairment Bradford LJ, Hardy WG eds New York: Grune and Stratton 1979, $16: 234-7$. 